\title{
Planned Number of Female Subjects
}

National Cancer Institute

\section{Source}

National Cancer Institute. Planned Number of Female Subjects. NCI Thesaurus. Code C90437.

The intended quantity of female participants. 